\title{
Comparison of the haemodynamic responses to laryngoscopy and intubation with MacIntosh and McCoy laryngoscopy
}

\author{
Authors \\ Dr Naqeeb Hassan ${ }^{1}$, Dr Mohammad Sadiq ${ }^{2}$, Tantry Tariq Gani ${ }^{3}$ \\ ${ }^{1}$ Postgraduate, Department of Anesthesiology and Critical Care, Govt. Medical College, Srinagar \\ ${ }^{2}$ Asistant Professor, Department of Anesthesiology And critical care, Govt. Medical College, Srinagar \\ ${ }^{3}$ Senior Resident, Department of Anesthesiology and Critical Care \\ Corresponding Author \\ Tantry Tariq Gani \\ Email: tantarytariq2@gmail.com
}

\begin{abstract}
Background: Stress response to laryngoscopy and tracheal intubation have a profound influence on the circulatory parameters and the intracranial pressure. The mean increase in arterial pressure of the order of 20-25 $\mathrm{mmHg}$ with a maximum rise of 40-45 $\mathrm{mmHg}$ has been reported. This peak response occurs approximately 30-45 seconds after laryngoscopy and lasts less than ten minutes. Forces transmitted by the laryngoscope blades on the base of the tongue are assumed to be a major stimulus. Sympathoadrenal response arises from the stimulation of the supraglottic region by the laryngoscope blade. When planning the anaesthesia induction, these effects must be blunted as much as possible.

Materials and Methods: This observational study was conducted at SMHS hospital of government medical college Srinagar. The study was conducted over a period of one year and total number of 100 patients were scheduled for elective procedures by randomly allocating to either Macintosh or McCoy laryngoscopy group. Aim was to Comparision of haemodynamic responses between the two groups. Comparing the time of laryngoscopy and intubation between the two groups and Comparing the laryngeal visualization grading between two groups. An informed written consent was taken from all patients at the time of pre-anaesthetic examination. Laryngoscopy and intubation was performed by standardized anesthetic technique. Size 3 laryngoscope blade was used in all cases. Monitoring include: measurement of noninvasive BP, heart rate (HR), any dysrhythmia oxygen saturation, end-tidal carbon dioxide, concentration of inhalational anesthetic agent. All values were recorded before induction, immediately before and after laryngoscopy and tracheal intubation, every minute for 5 min following tracheal intubation, and then 10 min after intubation.

Results: The baseline characteristics of the patients in terms of age, weight, height, sex distribution, Mallampati grading and the difference was not statistically significant similar between both the groups which indicated that both the groups were comparable. Maximal rise in heart rate was seen immediately post insertion with mean (107.9) in group A and mean (97.2) in group B respectively, and maximal value of standard deviation was seen after 3 min after insertion 4.34 in group $A$ and 4.29 in group B. On comparison of blood and mean arterial pressure between two groups blood and mean arterial pressure was lower in group B with p statistically significant immediately post insertion, 1 min and $3 \mathrm{~min}$, and $p$ is statistically insignificant after $5 \mathrm{~min}$.

Conclusion: McCoy laryngoscope produces significantly less rise in hemodynamic parameters as compared to Macintosh laryngoscope during laryngoscopy and intubation.
\end{abstract}

Key Word: McCoy laryngoscope, MacIntosh blade, endotracheal intubation, pressor response. 


\section{INTRODUCTION}

October 16.1846, marks the most important day in the history of general anesthesia ${ }^{1}$. It is on this day WTG Mortan anesthetized Edward Gilbert Abbott, with ether using a poorly designed inhaler without much emphasis laid on airway management ${ }^{1}$. This bold and dangerous technique of Morton, lead to development of safer technique of airway management ${ }^{1}$. Airway management is the task with which an anaesthesiologist encounters routinely. Time to time different aids, devices and maneuvers are used to maintain the airway. A variety of laryngoscopes are in use to facilitate laryngoscopy and intubation. Many supraglottic devices are also available ${ }^{2}$.

Laryngoscopes where designed to view the larynx and adjacent structures, and most importantly for intubation, that can provoke adverse cardiovascular response. ${ }^{1}$ Stress response to laryngoscopy and tracheal intubation have a profound influence on the circulatory parameters and the intracranial pressure. $^{1,3}$ It has been documented since 1951, that this response manifests as tachycardia, hypertension, dysrhythmias and it may have deleterious respiratory, neurological and cardiovascular effects. ${ }^{4,5}$ The mean increase in arterial pressure of the order of $20-25 \mathrm{mmHg}$ with a maximum rise of $40-45 \mathrm{mmHg}$ has been reported $^{6}$. This peak response occurs approximately 30-45 seconds after laryngoscopy and lasts less than ten minutes ${ }^{7}$. This rise in blood pressure and heart rate on laryngoscopy and intubation is transient, highly variable and generally well tolerated in healthy patients. Patients with hypertension, coronary artery disease, cerebrovascular disease, thyrotoxicosis and various other diseases, this response may lead to dangerous complications like left ventricular failure, myocardial infarction, dysrhythmias or cerebral haemorrhage. Forces transmitted by the laryngoscope blades on the base of the tongue are assumed to be a major stimulus. ${ }^{1,3}$ Sympathoadrenal response arises from the stimulation of the supraglottic region by the laryngoscope blade .Tracheal tube placement and cuff inflation in infra-glottic region contributes only a little additional stimulation, ${ }^{8,9}$. There is also an increase in the serum catecholamine levels.

When planning the anaesthesia induction, these effects must be blunted as much as possible especially if the patient is in the high risk population, for example patients with coronary artery disease, asthma, elevated intracranial pressure and cerebral aneurysm. ${ }^{1,3}$ When laryngoscopy proves difficult, the force applied increases as the degree of difficulty increases ${ }^{10,11,12}$. The factors that can cause difficulty during intubation are - forward displacement of larynx, forward or prominent upper incisor teeth, backward displacement of the tongue because of anatomical problems, in such situations, elevation of the epiglottis may be difficult or impossible. Laryngoscope can provoke adverse cardiovascular response ${ }^{10}$. The mechanical stimulation of upper respiratory tract via epipharynx, laryngopharynx, the afferents are the purpose of inserting an endotracheal tube. Direct laryngoscopy and passage of a tracheal tube are noxious stimuli carried by glasso-pharangeal nerve and from tracheobronchial tree via the vagus nerve which enhances the activities of the cervical sympathetic afferent fibres resulting in transient rise in heart rate and blood pressure ${ }^{13,14,9}$. Pressor response to laryngoscopy and intubation is mediated via sympathetic nerves and efferent pathway is also composed of sympathetic nerves. ${ }^{11,9,15}$ Significant hypertension and tachycardia are associated with tracheal intubation underlight anaesthesia ${ }^{10}$. The magnitude of the response is greater with increasing force and duration of laryngoscopy ${ }^{10}$. The elevation in arterial pressure typically starts within 5 seconds of laryngoscopy, peaks in 1 to 2 minutes, and returns to control levels within 5 minutes. The mean increase in arterial pressure of the order of $20-25 \mathrm{mmHg}$ with a maximum rise of 40-45 mmHg has been reported. ${ }^{10}$ Such hemodynamic changes can result in undesirable effects like myocardial ischemia, raised intracranial tension, raised intraocular tension ${ }^{10}$. In susceptible patients particularly those with systemic hypertension, coronary heart disease, cerebrovascular disease and intracranial aneurysm, even these transient 
changes can result in potentially deleterious effects like left ventricular failure, Arrhythmias, myocardial ischemia, cerebral haemorrhage and rupture of cerebral aneurysm ${ }^{1,13}$. There are a number of ways to blunt these hemodynamic changes. They include minimizing the duration of laryngoscopy, the use of intravenous narcotics, lidocaine, vasodilators and beta- blocking agents, topical, modification of instruments and use of other intubating devises (e.g LMA) ${ }^{16,17}$, have been tried to obtund this haemodynamic response to laryngoscopy and intubation. ${ }^{18,5}$ but most of these have produce variable results ${ }^{10,1,13}$. Anesthetic literature has focused more on the pharmacological methods for obtundation of the response, and literature related to nonpharmacological methods, specifically laryngoscopy blade design, is limited ${ }^{19}$. The Macintosh laryngoscope is one of the most popular laryngoscopes used universally. It was designed by Sir Robert Macintosh in 1943 in Nuffield department of anaesthetics, ${ }^{20}$ In 1993, McCoy and Mirakhur introduced McCoy laryngoscope, a modification of the standard Macintosh blade, to facilitate intubation in cases of difficult visualization of the larynx. Differences have been reported in the view obtained with Macintosh laryngoscope blade and those with McCoy blade in its neutral position. McCoy blade in its neutral position produced a worse view than Macintosh $^{20}$. However, it has also been reported that among the patients with initial poor laryngoscope view, the McCoy blade might enable faster and easier tracheal intubation. In other studies, the significant increase in heart rate and arterial blood pressure has been reported after laryngoscopy using the Macintosh blade, however, the use of McCoy blade has not been associated with any significant change in either heart rate or arterial blood pressure ${ }^{21,3}$. Thus it differs from Macintosh blade in four aspects. It has a hinged tip to avoid the lifting force in the vallecula $^{22}$, a lever at the proximal end, a spring loaded drum and a connecting shaft. The McCoy laryngoscope was developed for anticipated difficult intubation. ${ }^{22}$ It requires less force for performing laryngoscopy ${ }^{21,22}$ and as a result may reduce the sympathoadrenal response to laryngoscopy, thus decreasing the pressor response associated with laryngoscopy. Use of McCoy blade laryngoscope avoids the lifting force in the vallecula and theoretically should lead to a lower hemodynamic response related to laryngoscopy and tracheal intubation ${ }^{19}$. The present study was conducted to compare the efficacy of McCoy laryngoscope in obtunding the pressor response to laryngoscopy and intubation as compared to the Macintosh blade

\section{Materials and Methods}

This observational study was conducted at SMHS hospital one of the associate hospital of government medical college Srinagar, after obtaining approval from institutional ethics committee. The study was conducted over a period of one year and total number of 100 patients were enrolled of age group 18-60yrs. on American Society of Anesthesiologists (ASA) 1 and 2 patients of either gender between 18 and 60 years scheduled for elective procedures by randomly allocating to either Macintosh (Group A) or McCoy laryngoscopy (Group B) groups.

Inclusion criteria: Patients undergoing elective surgeries, aged between 18- 60 years, Mallampati I and II and ASAI and ASAII.

Exclusion criteria: Patients with history of anticipated difficult intubation, diabetes, hypertension, chronic obstructive airway disease, ischemic heart disease, and/or cardiac arrhythmias. BMI more than 30 and those undergoing head and neck surgery will be excluded.

Aim and Objective: The objective of this study was to determine the effectiveness of McCoy laryngoscope in attenuating the pressor response secondary to laryngoscopy, compared to standard Macintosh laryngoscope in adult patients undergoing elective surgery.

Aim: Comparision of haemodynamic responses between the two groups, Comparing the time of laryngoscopy and intubation between the two groups and comparing the laryngeal visualization grading between two groups. 
Pre-anaesthetic check-up was done one day before the surgery and airway assessment was done using Mallampati classification. An informed written consent was taken from all patients at the time of pre- anaesthetic examination. All the patients were kept fasting for a period of 8 hours preoperatively. Patients received tab. pantoprazole $40 \mathrm{mg}$ per oral and tab. alprazolam $0.5 \mathrm{mg}$ per oral, night before surgery. On the day of surgery, an intravenous line was established and a ringer lactate infusion started. Patients then received inj. tramadol 1 $\mathrm{mg} / \mathrm{kg} \mathrm{i} / \mathrm{v}$ and inj. pantoprazole $40 \mathrm{mg} \mathrm{i} / \mathrm{v}$ before induction. A head-ring was placed under the occiput of the patient to obtain classical sniffing position.

Laryngoscopy and intubation was performed by one of the primary investigators who are familiar, experienced and trained with intubation using the McCoy laryngoscope. Only one attempt at intubation was allowed using the assigned airway device. Failed intubation defined as an intubation time $>40$ seconds, oesophageal intubation or $>2$ attempts at intubation. In case of failure, the patient was not be studied for the study. Standardized Anesthetic technique was applied. Patients were pre-oxygenated for three minutes using $6 \mathrm{~L} / \mathrm{min}$ of $100 \%$ oxygen via the circle system. Propofol $2 \mathrm{mg} / \mathrm{kg}$ intravenously (IV) Atracurium $0.5 \mathrm{mg} / \mathrm{kg}$ administered over $10 \mathrm{~s}$ to facilitate tracheal intubation . Laryngoscopy and intubation after $3 \mathrm{~min}$. The aim was to keep the apneic period during intubation to less than $30 \mathrm{~s}$. An assistant timed the period using a stop watch. A size $7.5 \mathrm{~mm}$ ID polyvinyl chloride tracheal tube in females and size $8.5 \mathrm{~mm}$ ID in males. Size 3 laryngoscope blade was used in all cases. No external pressure was applied. The duration of laryngoscopy and intubation was defined as the time taken from when the tip of the blade passed the incisors until the time when the tip of the blade passed out of the incisors after inserting the endotracheal tube. During intubation, laryngeal inlet was visualized and graded using Cormack and Lehane grading. Anaesthesia was maintained with $66 \%$ nitrous oxide, $33 \%$ oxygen, $0.6 \%-1 \%$ isoflurane and neuromuscular blockade was achieved with inj. atracurium by $0.1 \mathrm{mg} / \mathrm{kg} \mathrm{i} / \mathrm{v}$ as maintenance dose. At the end of surgery neuromuscular blockade was reversed with inj. neostigmine $0.05 \mathrm{mg} / \mathrm{kg} \mathrm{i} / \mathrm{v}$ and inj. glycopyrrolate $0.01 \mathrm{mg} / \mathrm{kg} \mathrm{i} / \mathrm{v}$ before extubation.

Monitoring include: measurement of noninvasive $\mathrm{BP}$, heart rate (HR), oxygen saturation, end-tidal carbon dioxide, concentration of inhalational anesthetic agent. All values were recorded before induction, immediately before and after laryngoscopy and tracheal intubation, every minute for $5 \mathrm{~min}$ following tracheal intubation, and then $10 \mathrm{~min}$ after intubation by an independent observer. Any dysrhythmias or ST segment changes was also recorded during this period.

\section{Results and Observations}

The results and observations obtained are depicted in the following tables and graphs.

\begin{tabular}{|l|c|c|c|c|c|}
\hline Table 1: Age distribution of studied patients \\
\hline Age (years) & \multicolumn{2}{|c|}{ Group A } & \multicolumn{2}{c|}{ Group B } & P-value \\
\hline & No. & \%age & No. & \%age & \\
\hline $18-29$ & 15 & 30 & 20 & 40 & 0.233 \\
\hline $30-39$ & 13 & 26 & 14 & 28 & \\
\hline $40-49$ & 10 & 20 & 10 & 20 & \\
\hline$\geq 50$ & 12 & 24 & 6 & 12 & \\
\hline Mean \pm SD & \multicolumn{6}{|c|}{$36.7 \pm 13.24$} & $33.7 \pm 10.56$ & \\
\hline
\end{tabular}

Majority of patients belonged to the age group of $18-29$ years $(30 \%)$ in Group A $(40 \%)$ in Group B $33.7 \pm 10.56$ Group B respectively with p-value with mean and SD36.7 \pm 13.24 Group A and 
Table 2: Gender distribution of studied patients

\begin{tabular}{|l|c|c|c|c|c|}
\hline Gender & \multicolumn{2}{|c|}{ Group A } & \multicolumn{2}{c|}{ Group B } & P-value \\
\hline & No. & \%age & No. & \%age & \\
\hline Male & 26 & 52 & 28 & 56 & 0.688 \\
\hline Female & 24 & 48 & 22 & 44 & \\
\hline Total & 50 & 100 & 50 & 100 & \\
\hline
\end{tabular}

The above table 2 shows gender distribution of studied patients with 26 male ( $52 \%$ ) in group A $(48 \%)$ in group A and 22female (44\%) and 28 male (56\%)in group B and 24 female respectively, and $\mathrm{P}$ - value 0.688 .

Table 3: Showing mean weight (kgs) among two groups

\begin{tabular}{|l|c|c|c|c|}
\hline Weight (kgs) & Mean & SD & Range & P-value \\
\hline Group A & 55.4 & 6.24 & $46-70$ & 0.244 \\
\hline Group B & 56.9 & 6.56 & $45-68$ & \\
\hline
\end{tabular}

Table showing comparison of weight (kgs) in and Range 46-70 in group A and mean 56.4, SD group A and group B with mean 55.4 ,SD 6.24

6.56 and range $45-68$ in group B respectively.

\begin{tabular}{|l|c|c|c|c|c|}
\hline Table 4: ASA status of studied patients among two groups \\
\hline ASA & \multicolumn{2}{|c|}{ Group A } & \multicolumn{2}{c|}{ Group B } & P-value \\
\hline & No. & \%age & No. & \%age & \\
\hline ASA I & 43 & 86 & 44 & 88 & 0.766 \\
\hline ASA II & 7 & 14 & 6 & 12 & \\
\hline Total & 50 & 100 & 50 & 100 & \\
\hline
\end{tabular}

Majority of studied patients had ASA I 43 in group A (86\%) and 44 group B (88\%), ASA II 7

in group A (14\%) and 6 in group $\mathrm{B}(12 \%)$ respectively, with $\mathrm{p}$ value $=0.766$.

\begin{tabular}{|l|c|c|c|c|c|}
\hline Table 5: Comparison of mean heart rate (beats/min) among two groups \\
\hline Hear Rate & \multicolumn{2}{|c|}{ Group A } & \multicolumn{2}{c|}{ Group B } & P-value \\
\hline & Mean & SD & Mean & SD & \\
\hline Pre Induction & 80.1 & 3.77 & 80.0 & 3.48 & 0.891 \\
\hline Post Induction & 79.1 & 3.63 & 78.9 & 3.78 & 0.788 \\
\hline Immediately Post Insertion & 107.9 & 4.28 & 97.2 & 4.20 & $<0.001^{*}$ \\
\hline 1 Min after Insertion & 101.2 & 4.21 & 93.5 & 4.16 & $<0.001^{*}$ \\
\hline 3 Min after Insertion & 90.8 & 4.34 & 88.1 & 4.29 & $0.002^{*}$ \\
\hline 5 Min after Insertion & 84.9 & 4.27 & 84.0 & 4.20 & 0.313 \\
\hline
\end{tabular}

*Statistically Significant Difference (P-value<0.05)

Maximal rise in heart rate was seen immediately post insertion with mean (107.9) in group A and mean (97.2 ) in group B respectively, and maximal value of standard deviation was seen after 3 min after insertion 4.34 in group $\mathrm{A}$ and 4.29 in group B.

Table 6: Comparison based on systolic blood pressure $(\mathrm{mmHg})$ between two groups

\begin{tabular}{|l|c|c|c|c|c|}
\hline SBP & \multicolumn{2}{|c|}{ Group A } & \multicolumn{2}{c|}{ Group B } & P-value \\
\hline Pre Induction & Mean & SD & Mean & SD & \\
\hline Post Induction & 123.9 & 3.03 & 124.3 & 2.37 & 0.464 \\
\hline Immediately Post Insertion & 122.1 & 3.34 & 122.5 & 2.50 & 0.543 \\
\hline 1 Min after Insertion & 154.9 & 3.25 & 144.7 & 2.56 & $<0.001 *$ \\
\hline 3 Min after Insertion & 147.2 & 3.19 & 137.3 & 2.49 & $<0.001^{*}$ \\
\hline 5 Min after Insertion & 130.8 & 3.54 & 124.9 & 2.46 & $<0.001^{*}$ \\
\hline
\end{tabular}

*Statistically Significant Difference (P-value $<0.05)$

Systolic blood pressure between two groups shows that maximum rise of systolic blood pressure occur immediately post insertion with

mean and SD 154.9 \pm 3.25 in group $A$ and $144.7 \pm 2.56$ in group $\mathrm{B}$ respectively, $\mathrm{p}$ significantly significant immediately pot 
intubation, $1 \mathrm{~min}$ and $3 \mathrm{~min}$.after $5 \mathrm{~min} \mathrm{p}$ is

statistically significant.

Table 7: Comparison based on diastolic blood pressure ( $\mathrm{mmHg}$ ) between two groups

\begin{tabular}{|l|c|c|c|c|c|}
\hline DBP & \multicolumn{2}{|c|}{ Group A } & \multicolumn{2}{c|}{ Group B } & P-value \\
\hline & Mean & SD & Mean & SD & \\
\hline Pre Induction & 79.9 & 2.55 & 80.5 & 2.95 & 0.312 \\
\hline Post Induction & 78.1 & 2.88 & 78.3 & 3.07 & 0.763 \\
\hline Immediately Post Insertion & 101.6 & 2.63 & 94.8 & 3.14 & $<0.001^{*}$ \\
\hline 1 Min after Insertion & 98.5 & 3.11 & 87.5 & 3.06 & $<0.001^{*}$ \\
\hline 3 Min after Insertion & 85.3 & 3.13 & 82.1 & 3.12 & $<0.001^{*}$ \\
\hline 5 Min after Insertion & 81.1 & 2.56 & 80.4 & 3.08 & 0.247 \\
\hline
\end{tabular}

Table 8: Comparison based on mean arterial pressure ( $\mathrm{mmHg}$ ) between two groups

\begin{tabular}{|l|c|c|c|c|c|}
\hline MAP & \multicolumn{2}{|c|}{ Group A } & \multicolumn{2}{c|}{ Group B } & P-value \\
\hline & Mean & SD & Mean & SD & \\
\hline Pre Induction & 94.6 & 2.56 & 95.1 & 2.66 & 0.335 \\
\hline Post Induction & 92.8 & 2.91 & 93.0 & 2.70 & 0.670 \\
\hline Immediately Post Insertion & 119.4 & 2.44 & 111.4 & 2.82 & $<0.001^{*}$ \\
\hline 1 Min after Insertion & 114.7 & 2.83 & 104.1 & 2.78 & $<0.001^{*}$ \\
\hline 3 Min after Insertion & 100.5 & 2.98 & 96.4 & 2.81 & $<0.001^{*}$ \\
\hline 5 Min after Insertion & 95.3 & 2.52 & 94.6 & 2.80 & 0.176 \\
\hline
\end{tabular}

*Statistically Significant Difference $(\mathbf{P}$-value $<0.05)$

Above table shows that mean arterial pressure (mmhg) is lower in group B than group A with $\mathrm{p}$ value $<0.05$ statistically significant immediately post insertion, $1 \mathrm{~min}$ and $3 \mathrm{~min}$ after insertion after 5 min of insertion $p$ value was seen to be statistically insignificant.

\section{Discussion}

Several methods have been used to blunt the cardiovascular response associated with laryngoscopy and intubation with more focus on pharmacological methods as compared to nonpharmacological methods. There is limited literature regarding the influence of the type of laryngoscope blade on hemodynamic response to laryngoscopy and intubation. The McCoy levering blade differed from Macintosh blade in four respects, it has a hinged tip, a lever at proximal end, a spring loaded drum and a connecting shaft. The hinged tip blades controlled by a lever on the handle of laryngoscope allow elevation of epiglottis while decreasing over all movement. This unique design has shown two advantages over Macintosh, first the less force applied during laryngoscope and thus stress response is reduced.
Secondly, difficult laryngoscopic visualization may be improved by lifting the epiglottis.

The present study was conducted by using McCoy's and Macintosh laryngoscope to compare haemodynamic changes resulting during laryngoscope and intubation with the two blades in predicted easy and difficult airway. The baseline characteristics of the patients in terms of age, weight, height, sex distribution, Mallampati grading and the difference was not statistically significant similar between both the groups which indicated that both the groups were comparable as shown in table no 1-4 respectively. This is similar to the results Mukta Jitendra et $\mathrm{al}^{23}$ and $\mathrm{S}$ Singhal, $\mathrm{Neha}^{5}$ were the study groups were comparable in terms of age, weight, height, sex distribution, Mallampati grading and the difference was not statistically significant.

The present study was undertaken to evaluate the effectiveness of McCoy laryngoscope, in attenuating the pressor response secondary to laryngoscopy and intubation, as compared to Macintosh laryngoscope. In both Groups, significant increase in heart rate as compared to baseline was observed after laryngoscopy and 
intubation. While doing inter group comparison, we found that mean heart rate was lower in Group B as compared to Group A immediately after , 1 and 3 minutes after intubation $97.2 \pm 4.20$ vs 107.9 $\pm 4.28,93.5 \pm 4.16$ vs $101.2 \pm 4.21$ and $88.1 \pm 4.29$ vs $90.8 \pm 4.34$ which was statistically significant $(\mathrm{p}<0.05)$. Following 5 minutes, the difference was statistically insignificant as cited in table no. 5 and graph no 1 . Our observations were in conformity with the observation in the studies of Mehtab A Haidry and Fauzia A Khan ${ }^{24}$, Mukta Jitendra et $\mathrm{al}^{23}$,S Singhal and Neha ${ }^{5}$, and Nishiyama et al. ${ }^{3}$ were significant increase in heart rate as compared to baseline was observed after laryngoscopy and intubation ,in both groups. Also while doing inter group comparision, the mean heart rate was lower in McCoy group as compared to Macintosh laryngoscope.

The enrolled patients when subjected with laryngoscopy and intubation, to evaluate the effectiveness of McCoy laryngoscope, in attenuating the pressor response secondary to laryngoscopy and intubation, as compared to Macintosh laryngoscope The maximum in SBP, DBP and MAP was lower in Group B as compared to Group A immediately after and at 1 and 3 minutes after intubation which was statistically significant. Following 5 minutes, the difference was statistically insignificant as shown in table 6,7 and 8 and graph 2 and 3 respectively.

Hemodynamic response was similar in our study as observed by McCoy et.al ${ }^{21}$. Major cause of sympatho-adrenal response is believed to arise from stimulation of supraglotic region by the laryngoscope blade while endotracheal intubation and cuff inflation contributing little additional stimulation. We also observed that maximum rise was after laryngoscopy which increased a little further after intubation. It is established that forces exerted by the laryngoscope blade on the base of tongue are assumed to be the major stimuli, which result in exaggerated response to laryngoscopy. McCoy blade was designed in such a way to decrease the forces exerted on the base of tongue so that the pressure response to laryngoscopy and intubation is minimized ${ }^{25}$.Our results were consistent with the results of various previous studies. McCoy et $\mathrm{al}^{26}$ compared cardiovascular changes and catecholamine concentrations in 20 patients before and after laryngoscopy with either Macintosh or McCoy laryngoscopes ${ }^{26}$. Significant increase in heart rate $(33 \%)$, arterial blood pressure $(27 \%)$ and slight increase in catecholamine levels were noted with Macintosh laryngoscope as against McCoy laryngoscope where no significant change in either heart rate or arterial blood pressure was found. Nishiyama et $\mathrm{al}^{3} \quad$ compared stress responses during laryngoscopy using three different laryngoscopesMacintosh, Miller and McCoy. Blood pressure, heart rate and plasma catecholamine levels were measured before, during and after laryngoscopy without tracheal intubation. Systolic blood pressure was significantly higher in Miller than in other groups. Plasma epinephrine concentration in McCoy group were significantly lower than in other groups. Heart rate and plasma norepinephrine concentration were not different among the three groups. But in our study, heart rate did rise significantly till 7 minutes after intubation and the heart rate changes were significantly higher in Macintosh group as compared to McCoy group. This could be explained by the fact that Nishiyama ${ }^{3}$ only studied response to laryngoscopy and not tracheal intubation. Tracheal intubation has been shown to affect heart rate more than laryngoscopy. Tiwari et $\mathrm{al}^{27}$ compared the two blades in 180 neurosurgical patients. They found that use of McCoy laryngoscope resulted in lesser change in heart rate and blood pressure compared to Macintosh laryngoscope when fentanyl was not used in obtundation of stress response. However, when fentanyl was given as an analgesic, no difference was observed between the group. Similar to our study, Singhal et $\mathrm{al}^{5}$ compared hemodynamic response to laryngoscopy and intubation using Macintosh and McCoy laryngoscopes in 100 patients. They found that significant rise in heart rate, systolic blood pressure, diastolic blood pressure and mean arterial pressure was seen in both the groups but 
this rise was significantly more with Macintosh laryngoscope as compared to McCoy laryngoscope. Bhosle et $\mathrm{al}^{11}$ compared hemodynamic response with McCoy and Macintosh laryngoscopes in 200 patients. The percentage increase in heart rate and mean arterial pressure from baseline after intubation and at one minute was found to be higher in Macintosh group as compared to McCoy group and was statistically significant. The parameters returned to baseline in 3 to 5 minutes. Haidry et $\mathrm{al}^{24}$ compared hemodynamic response to laryngoscopy and intubation using Macintosh and McCoy laryngoscope in 60 patients. They found that hemodynamic changes with the use of McCoy laryngoscope were lesser in magnitude as compared to Macintosh laryngoscope We also got similar results in our study.

\section{Conclusion}

From the above observations it is concluded that McCoy laryngoscope, primarily devised for difficult intubation, produces significantly less rise in hemodynamic parameters as compared to Macintosh laryngoscope. It requires less force for performing laryngoscopy and as a result reduces the sympatho-adrenal response to laryngoscopy, thereby decreasing the pressor response. Therefore use of McCoy laryngoscope can serve as an additional tool along with different pharmacological agents for obtunding the pressor response. Thus we draw a conclusion from this study that McCoy laryngoscope produces significantly less rise in hemodynamic parameters as compared to Macintosh laryngoscope during laryngoscopy and intubation.

\section{Reference}

1. Miller DR. Airway management of Anaesthesia. $7^{\text {th }}$ Ed., Churhill Livingstone; 2005: 1636.

2. Zia Arshad, Haider Abbas, Jaishree Bogra, Sulekha Saxena. Comparison of Laryngoscopic View and Hemodynamic Changes with Flexitip McCoy and Macintosh Laryngoscope Blade in
Predicted Easy and Difficult Airway. Journal of Anesthesiology. 2013;3:278-28.

3. Nishiyama $T$, Higashizawa $T$, Bito $H$, Konishi A, Sakai T. Which larygnosocpe is the most stressful in laryngoscopy Macintosh, Miller or McCoy? Masui 1997; 46: 1519-24.

4. King BD, Harris LC, Greifenstein FE, Elder JD, Dripps RD. Reflex circulatory sponses to direct laryngoscopy and tracheal intubation performed during general anesthesia. Anesthesiology 1951; 12:556-66.

5. S Singhal and Neha: Haemodynamic response to laryngoscopy and intubation: Comparison of the McCoy and Macintosh laryngoscope. The Internert Journal of Anaesthesiology; 2008, Vol 17 Number 1.

6. Forbes AM, Dally FG. Acute hypertension during induction of anaesthesia and endotracheal intubation in normotensive man. Br J. Anaesth 1970; 42: 618-24.

7. Stoelting RK. Circulatory changes during direct laryngoscopy and tracheal intubation: Influence of duration of laryngoscopy with or without lidocaine. Anesthesiology 1977; 47: 381-84.

8. Jain S, Maroof M, Verma V, Alam M, Gogias Khan RM. Truview EvO2 laryngoscopy is superior to Macintosh laryngoscopy in terms of force used, glottis view and haemodynamic changes. Anesth Analg. 2007;104:S-119.

9. Shribman AJ, Smith G, Achola KJ. Cardiovascular and catechlamine responses to laryngoscopy with and without endotracheal intubation. $\mathrm{Br} \mathrm{J}$ Anaesth. 1987; 59:295-9.

10. Braude N, Clements EAF, Hodges UM, Andrews BP. The pressor response and laryngeal mask insertion - a comparison with tracheal intubation Anaesthesia, 1989;44: 551-554.

11. Bhosle P, Aphale S, Bansal M. A comparison of circulatory response to laryngoscopy and intubation with 
Macintosh and McCoy blade. The Internet Journal of Anaesthesiology 2013; 32:1.

12. J. B. Li, Y. C. Xiong, X. L. Wang, X. H. Fan, Y. Li and H. Xu, et al., "An Evaluation of the Truview EVO2 Laryngoscope," Anaesthesia,. 2007; 62: 940943.

13. Sarabjit Kaur, Asha Gupta, Ranjana, Rita. Intubating conditions and stress response to laryngoscopy: Comparison between Macintosh and levering (McCoy's Type) Laryngoscope. Anaesth. Clin Pharmacol 2009; 25 (3): 333-336.

14. Shimoda O, Ikuta Y, Isayama S, Sakamoto M, Terasaki H. Skin vasomotor reflex induced by laryngoscopy: Comparison of the McCoy and Macintosh blades. $\mathrm{Br} \mathrm{J}$ Anaesth. 1997; 79:714-98.

15. Tewari P, Gupta D, Kumar A, Singh U. Opioid sparing during endotracheal intubation using McCoy laryngoscope in neurosurgical patients: The comparison of haemodynamic changes with Macintosh blade in a randomized trial. J Postgrad Med. 2005; 51:260-5.

16. Han TS, Kin JA, Park NG, Lee SM, Cho Hs, Chung IS. A comparison of the effects of different type of laryngoscope on haemodynamics. McCoy versus the Macintosh blade. Korean J Anesthesiol. 1999;37:398-41.

17. Hyun Jung Shin, Young Duck Shin and Sang Tae Kim.The effect of tracheal intubation with the McCoy or Macintosh laryngoscope on the blood pressure and heart rate during propofol -remifentanil induction. Korean J Anesthesiol.2009; 56(4):388-91.

18. Gill YS, Lee GY, Chung RK, Kim DY, Kang SY. Effect of laryngoscopic and tracheal intubation duration on hemodynamic response during anesthetic induction with thiopental, fentanyl and rocuronium. Korean J Anesthesiol. 2005; 49:147-51.
19. B Beilin, I Z Yardeni, V. Smolyarenko A, Seidel, E Ram and E Mayburo,: Comparison of the flexible levering laryngoscope with the English Macintosh Laryngoscope in patients with a poor laryngoscopic view, Anaesthesia, 2005; 60: 400-405.

20. Macintosh RR. A new laryngoscope. Lancet 1943; 1: 205.

21. E P McCoy, R K Mirakhur, C. Rafferty H, Bunting and B A Austin : A comparison of the forces exerted during laryngoscopy, the Macintosh versus McCoy blade, Anaesthesia 1996; 51: 912-915.

22. M. Barak, P. Philipchuck, P. Abecassis and Y. Katz, "A Comparison of the Truview Blade with the Macintosh Blade in Adult Patients," Anaesthesia, Vol. 62, No. 8, 2007, pp. 827-833.

23. E P McCoy, R K Mirakhur,: Cardiovascular response to laryngoscopy a comparison between the McCoy and Macintosh blade Br. J. A'naesthesia 1996; 76: 17-18.

24. Mallampati SR. Clinical sign to predict tracheal intubation (hypothesis) condition. Anaesthesia Soceity Journal 1983; 30: $316-317$.

25. McCoy EP, Mirakhur RK The levering laryngoscope. Anaesthesia1993;48:516-19.

26. Mukta Jitendra, Sonal Sharma, Madan Katoch, Smriti Gulati, Heena Gupta.Comparison of Hemodynamic Response to Tracheal Intubation with Macintosh and Mccoy Laryngoscopes. Journal of Evolution of Medical and Dental Sciences 2015; 4 ( 50):8676-8684.

27. Fauzia Rehman Khan, Pallavi Ahluwalia, Mohammad Aslam, Dr. Arvind Kumar Morya.Comparative study of cardiovascular response and POGO scorimg with McCoy ,Macintosh and Truview EVO-2 .Scholars journal of applied medical science ,2015 ;3(3g):1486-89. 
28. Haidry MA, Khan FA. Comparison of hemodynamic response to tracheal intubation with Macintosh and McCoy laryngoscopes. J Anaesthesiol Clin Pharmacol 2013; 29: 196-99. 